\section{Pollinator-mediated selection and floral evolution: from pollination ecology to macroevolution}

\section{Pollination as an evolutionary process}

Plant-pollinator relationships have been a central topic in the study of floral evolution ever since Darwin (1859, 1862); they have been cited as a classic example of evolution in response to selection mediated through biotic interactions (Grant, 1949; van der Pijl, 1961; Fægri \& van der Pijl, 1979; Proctor et al., 1996). Pollination biology is presently a major discipline that explores the mutualistic interactions among species. As an ecological discipline, it describes the association between floral traits and pollinator behaviour, the mechanical fit between the pollinator and the pollen-bearing and pollen-receiving structures, and the importance of biotic and abiotic interactions at the species to community levels (e.g. Dafni, 1992; Mitchell et al., 2009; Vázquez et al., 2009; Morris et al., 2010). Moving beyond the mechanisms and patterns of interactions to the evolutionary processes that maintain or change them requires understanding the genetic basis of floral traits, the phenotypic basis of selection and the evolutionary consequences of these interactions. Indeed, many studies have attempted to place pollination ecology in an explicitly evolutionary framework (e.g. Grant, 1949; van der Pijl, 1961; Levin \& Kerster, 1967; Schemske \& Bradshaw, 1999; Armbruster et al., 2005; Muchhala, 2007; Vereecken et al., 2010). Nevertheless, there are very few studies in which the full path, from molecular patterns at the genome level and pollinator-mediated selection on phenotype, to the final evolutionary consequences, has been elucidated (Campbell et al., 1991; Bradshaw \& Schemske, 2003; Hoballah et al., 2007). It is an ideal time to assess recent progress in taking evolutionary approaches to investigate pollination biology, with the aim of developing a cohesive framework for understanding the role of pollination in floral evolution. This issue of New Phytologist contains a special feature, based partly on a European Society for Evolutionary Biology symposium held in Turin in August 2009, that gathers together studies aimed at advancing our evolutionary understanding of pollination and setting a framework for future work.

\section{Pollination genetics - prepollination processes}

The genetic basis of floral traits is a key factor in determining evolutionary responses to pollinator-mediated selection on floral phenotype. There are two general approaches used to assess the genetic basis of floral phenotype. The first is to estimate the quantitative-genetic architecture of floral traits; this determines the evolvability and genetic constraints on trait evolution (Hansen et al., 2003b; Hansen, 2006; Hansen \& Houle, 2008). Heritability is the most common parameter estimated in quantitative genetic studies, and quantitative genetic studies of flowers show most traits to have significantly nonzero heritability values (Ashman \& Majetic, 2006). Heritability is often not the best measure of evolutionary capacity, and a few studies use direct estimates of evolvability (Houle, 1992; Hansen \& Houle, 2008) to predict the capacity of floral traits to respond to natural selection (Hansen et al., 2003a,b; Lankinen et al., 2007). Another important quantitative genetic parameter is the genetic correlation between floral traits; this estimates the effects of pleiotropy and/or linkage (e.g. Armbruster, 1991; Campbell et al., 1994; Conner, 2002; Hansen et al., 2003a). Bolstad et al. (pp. 370-384) take advantage of such quantitative-genetic information to disentangle the selection on signal from selection on reward.

The second approach used to assess the genetic basis of floral traits influencing pollination interactions is to identify the exact gene or genes and the molecular mechanisms that control floral traits (reviewed in Sapir, 2009b). The molecular variation of the exact gene that controls the phenotypic variation is not easy to determine for plants lacking full annotated genomes. Indeed, only a handful of studies have connected this variation to pollinator behaviour (Bradshaw \& Schemske, 2003; Hoballah et al., 2007; Kessler et al., 2008; Martin et al., 2008; Sapir, 2009a). This frontier seems promising, although demanding. The New Phytologist special feature does not cover this approach, but we look forward to future technological breakthroughs that will enable us to connect molecular plant genetics to pollinators' behaviour in nonmodel plants.

\section{Pollinator-mediated selection and genetics}

The two genetic components of floral evolution described above are largely prepollination phenomena. The evolutionary response to selection depends on heritability and genetic variation (prepollination), but also on selection and 
processes following the pollination itself. Analysis of pollinator-mediated phenotypic selection is a powerful tool for assessing the potential evolutionary significance of a trait (reviewed in Harder \& Johnson, 2009), and this approach has been taken by Sletvold et al. (pp. 385-392), Parachnowitsch \& Kessler (pp. 393-402) and Bolstad et al. (pp. 370-384) in this issue. However, response to selection must be assessed in the next generation to ascertain the true evolutionary significance of trait variation. On a broader scale, gene flow mediated by pollinators can promote assortative mating among plants and lead to speciation (Jones, 2001; Sargent \& Otto, 2006; Gegear \& Burns, 2007). Correlation between mates can be estimated by comparing the regression of offspring phenotype over one parent, which is inflated by assortative mating, to the regression over mid-parent, which is not (Weis \& Kossler, 2004). Overall, the distribution of traits in the offspring generation, at both phenotypic and genotypic levels, has not been studied in sufficient detail to draw conclusions about the effects of assortative mating mediated by pollinators.

Floral specialization and adaptive radiations in pollination are among the most widely discussed concepts in the field, dating back to at least Sprengel (1793) and Darwin (1862, 1877). Recent interest has focused on the role of pollinator differences in driving speciation and hence diversification (e.g. Grant, 1949; Schemske \& Bradshaw, 1999; Kay \& Sargent, 2009; Venail et al., 2010). However, there remains uncertainty in just how floral specialization relates to species diversification - through cause (e.g. Dodd et al., 2000; Sargent, 2004), effect, or spurious correlation (Armbruster \& Muchhala, 2009). There is also uncertainty in just how common ecological specialization is in pollination, and how important it is in speciation (Waser et al., 1996; Johnson \& Steiner, 2000; Fenster et al., 2004). It is also not clear whether generalization in pollination leads to specialization during pollinator-mediated adaptive divergence, or vice versa (Martén-Rodríguez et al., pp. 403417).

Diversifications in pollination systems are usually driven by adaptation to new pollinators (e.g. Armbruster \& Baldwin, 1998; Kay \& Sargent, 2009; Schluter, 2009; Alonso et al., 2010). Alternatively, diversification in floral traits may not be adaptive in that floral diversification can occur for reasons not associated with their present function in pollination (nonadaptive radiations; Levin, 2000; Armbruster, 2002). Distinguishing among the various possible causes of diversification in pollination systems within a discrete clade is challenging but important for understanding adaptation, speciation and the macroevolutionary patterns generated by these processes. As phylogenies become available for more groups, our ability to trace evolutionary change in pollination ecology will improve. It will soon be possible to assess evolutionary patterns of diversification in a large sample of clades with fully elucidated phylogenies and pollination ecologies (Smith et al., 2008), as exemplified by four papers in this volume (see the following section).

\section{An evolutionary approach to pollination ecology}

It is clear from the preceding discussion that much can be gained by approaching pollination in an evolutionarygenetic framework. We emphasize the need for more knowledge about the genetic basis of traits influencing pollinator behaviour, as well as the genetic responses to pollinatormediated selection. These effects together determine the course of future evolutionary change in floral traits and plant-pollinator interactions. We emphasize studying pollination as an evolutionary process, and the importance of injecting evolutionary genetics into pollination studies, above and beyond evolution's direct ecological significance (see Thompson, 1998).

This New Phytologist special feature brings together several examples of this approach. Vallejo-Marin et al. (pp. 418-425) examine the correlations of floral traits associated with reward and advertisement, using a phylogenetic perspective to ascertain evolutionary origins. Three papers in this issue examine the selection exerted on floral traits. Sletvold et al. (pp. 385-392) and Parachnowitsch \& Kessler (pp. 393-402) show experimentally that floral traits are indeed under pollinatormediated selection, and Bolstad et al. (pp. 370-384) partition this selection into its effect on advertisement vs reward traits. In order to detect the postpollination outcome, Rymer et al. (pp. 426-436) used maternal and paternal fitness to assess assortative mating that may isolate sympatric Gladiolus morphs. Surprisingly, they found a lack of assortative mating and predicted that the morphs will introgress. This study in particular raises the need for more tests of the paradigm of pollinatormediated ecological speciation. The use of phylogenetic analyses provide a basis to associate speciation in deceptive orchids with the diversification of chemical odours (Peakall et al., pp. 437-450), and to show the direction of evolution from specialization to generalization in the Caribbean flora (Martén-Rodríguez et al., pp. 403-417). Finally, the use of phylogenetic analyses to study the evolution of pollination systems is reviewed by Smith (pp. 354-363).

We think that, despite the extensive literature on the effects of floral traits on pollinators and vice versa, the field is still in the early stages of moving from describing patterns to understanding processes. The full integration of molecular and/or quantitative genetics as prepollination processes with measures of phenotypic selection and postpollination 
New

Phytologist

processes is a promising direction for future studies of evolutionary pollination ecology.

\section{Yuval Sapir ${ }^{1}$ and W. Scott Armbruster ${ }^{2}$}

${ }^{1}$ The Botanical Garden, Department of Plant Sciences, Tel Aviv University, Ramat Aviv, Tel Aviv 69978, Israel (email sapiry@post.tau.ac.il)

${ }^{2}$ School of Biological Sciences, University of Portsmouth, King Henry I St., Portsmouth, PO1 2DY, UK; and Institute of Arctic Biology, University of Alaska, 311 Irving, Fairbanks, AK 99775 USA (email scott.armbruster@port.ac.uk)

\section{References}

Alonso C, Vamosi JC, Knight TM, Steets JA, Ashman T-L. 2010. Is reproduction of endemic plant species particularly pollen limited in biodiversity hotspots? Oikos 119: 1192-1200.

Armbruster WS. 1991. Multilevel analysis of morphometric data from natural plant-populations - insights into ontogenic, genetic, and selective correlations in Dalechampia scandens. Evolution 45: 1229-1244.

Armbruster WS. 2002. Can indirect selection and genetic context contribute to trait diversification? A transition-probability study of blossom-colour evolution in two genera. Journal of Evolutionary Biology 15: 468-486.

Armbruster WS, Antonsen L, Pélabon C. 2005. Phenotypic selection on Dalechampia blossoms: honest signaling affects pollination success. Ecology 86: 3323-3333.

Armbruster WS, Baldwin BG. 1998. Switch from specialized to generalized pollination. Nature 394: 632.

Armbruster WS, Muchhala N. 2009. Associations between floral specialization and species diversity: cause, effect, or correlation? Evolutionary Ecology 23: 159-179.

Ashman TL, Majetic CJ. 2006. Genetic constraints on floral evolution: a review and evaluation of patterns. Heredity 96: 343-352.

Bolstad GH, Armbruster WS, Pélabon C, P'érez-Barrales R, Hansen TF. 2010. Direct selection at the blossom level on floral reward by pollinators in a natural population of Dalechampia schottii: fulldisclosure honesty? New Phytologist 188: 370-384.

Bradshaw HD, Schemske DW. 2003. Allele substitution at a flower colour locus produces a pollinator shift in monkeyflowers. Nature 426: 176-178.

Campbell DR, Waser NM, Price MV. 1994. Indirect selection of stigma position in Ipomopsis aggregata via a genetically correlated trait. Evolution 48: 55-68.

Campbell DR, Waser NM, Price MV, Lynch EA, Mitchell RJ. 1991. Components of phenotypic selection: pollen export and flower corolla width in Ipomopsis aggregata. Evolution 45: 1458-1467.

Conner JK. 2002. Genetic mechanisms of floral trait correlations in a natural population. Nature 420: 407-410.

Dafni A. 1992. Pollination ecology: a practical approach. Oxford, UK: Oxford University Press.

Darwin CR. 1859. On the origin of species by means of natural selection, or the preservation of favoured races in the struggle for life. London, UK: John Murray.

Darwin CR. 1862. On the various contrivances by which British and foreign orchids are fertilised by insects. London, UK: John Murray.

Darwin CR. 1877. The different forms of flowers on plants of the same species. London, UK: John Murray.

Dodd ME, Silvertown J, Chase MW. 2000. Phylogenetic analysis of trait evolution and species diversity variation among angiosperm families. Evolution 53: 732-744.
Fægri K, van der Pijl L. 1979. The principles of pollination ecology. Oxford, UK: Pergamon Press.

Fenster CB, Armbuster WS, Wilson P, Dudash MR, Thomson JD. 2004. Pollination syndromes and floral specialization. Annual Review of Ecology, Evolution and Systematics 35: 375-403.

Gegear RJ, Burns JG. 2007. The birds, the bees, and the virtual flowers: can pollinator behavior drive ecological speciation in flowering plants? The American Naturalist 170: 551-566.

Grant V. 1949. Pollination systems as isolating mechanisms in angiosperms. Evolution 3: 82-97.

Hansen TF. 2006. The evolution of genetic architecture. Annual Review of Ecology, Evolution, and Systematics 37: 123-157.

Hansen TF, Armbruster WS, Carlson ML, Pélabon C. 2003a Evolvability and genetic constraint in Dalechampia blossoms: genetic correlations and conditional evolvability. Journal of Experimental Zoology. Molecular and Developmental Evolution 296B: 23-39.

Hansen TF, Houle D. 2008. Measuring and comparing evolvability and constraint in multivariate characters. Journal of Evolutionary Biology 21: 1201-1219.

Hansen TF, Pélabon C, Armbruster WS, Carlson ML. 2003b. Evolvability and genetic constraint in Dalechampia blossoms: components of variance measures of evolvability. Journal for Evolutionary Biology 16: 754-766.

Harder LD, Johnson SD. 2009. Darwin's beautiful contrivances: evolutionary and functional evidence for floral adaptation. New Phytologist 183: 530-545.

Hoballah ME, Gubitz T, Stuurman J, Broger L, Barone M, Mandel T, Dell'Olivo A, Arnold M, Kuhlemeier C. 2007. Single gene-mediated shift in pollinator attraction in Petunia. Plant Cell 19: 779-790.

Houle D. 1992. Comparing evolvability and variability of quantitative traits. Genetics 130: 195-204.

Johnson SD, Steiner KE. 2000. Generalization versus specialization in plant pollination systems. Trends in Evolution and Ecology 15: 140-143.

Jones KN. 2001. Pollinator-mediated assortative mating: causes and consequences. In: Chittka L, Thomson JD, eds. Cognitive ecology of pollination: animal behavior and floral evolution. Cambridge, UK: Cambridge University Press, 259-273.

Kay KM, Sargent RD. 2009. The role of animal pollination in plant speciation: integrating ecology, geography, and genetics. Annual Review of Ecology, Evolution, and Systematics 40: 637-656.

Kessler D, Gase K, Baldwin IT. 2008. Field experiments with transformed plants reveal the sense of floral scents. Science 321: 1200-1202.

Lankinen A, Armbruster WS, Antonsen L. 2007. Delayed stigma receptivity in Collinsia heterophylla (Plantaginaceae): genetic variation and possible adaptive significance in relation to pollen competition, delayed self-pollination, and mating-system evolution. American Journal of Botany 94: 1183-1192.

Levin DA. 2000. The origin, expansion, and demise of plant species. New York, NY, USA: Oxford University Press.

Levin DA, Kerster HW. 1967. Natural selection for reproductive isolation in Phlox. Evolution 21: 679-687.

Martén-Rodríguez S, Fenster CB, Agnarsson I, Skog LE, Zimmer EA. 2010. Evolutionary breakdown of pollination specialization in a Caribbean plant radiation. New Phytologist 188: 403-417.

Martin NH, Sapir Y, Arnold ML. 2008. The genetic architecture of reproductive isolation in Louisiana Irises: pollination syndromes and pollinator preferences. Evolution 62: 740-752.

Mitchell RJ, Flanagan RJ, Brown BJ, Waser NM, Karron JD. 2009. New frontiers in competition for pollination. Annals of Botany 103: 1403-1413.

Morris WF, Vazquez DP, Chacoff NP. 2010. Benefit and cost curves for typical pollination mutualisms. Ecology 91: 1276-1285.

Muchhala N. 2007. Adaptive trade-off in floral morphology mediates specialization for flowers pollinated by bats and hummingbirds. The American Naturalist 169: 494-504. 
Parachnowitsch AL, Kessler A. 2010. Pollinators exert natural selection on flower size and floral display in Penstemon digitalis. New Phytologist 188: 393-402.

Peakall R, Ebert D, Poldy J, Barrow RA, Francke W, Bower CC, Schiestl FP. 2010. Pollinator specificity, floral odour chemistry and the phylogeny of Australian sexually deceptive Chiloglottis orchids: implications for pollinator-driven speciation. New Phytologist 188: 437-450.

van der Pijl L. 1961. Ecological aspects of flower evolution. II. Zoophilous flower classes. Evolution 15: 44-59.

Proctor M, Yeo P, Lack A. 1996. The natural history of pollination. London, UK: Harper Collins.

Rymer PD, Johnson SD, Savolainen V. 2010. Pollinator behaviour and plant speciation: can assortative mating and disruptive selection maintain distinct floral morphs in sympatry? New Phytologist 188: 426436.

Sapir Y. 2009a. Effects of floral traits and plant genetic composition on pollinator behavior. Arthropod-Plant Interactions 3: 115-129.

Sapir Y. 2009b. Pollination genetics: using molecular genetic underlying floral traits to study pollination ecology in an evolutionary context. Israel Journal of Plant Sciences 57: 141-149.

Sargent RD. 2004. Floral symmetry affects speciation rates in angiosperms. Proceedings of the Royal Society B: Biological Sciences 271: 603-608.

Sargent RD, Otto SP. 2006. The role of local species abundance in the evolution of pollinator attraction in flowering plants. The American Naturalist 167: 67-80.

Schemske DW, Bradshaw HD. 1999. Pollinator preference and the evolution of floral traits in monkeyflowers (Mimulus). Proceedings of the National Academy of Sciences, USA 96: 11910-11915.

Schluter D. 2009. Evidence for ecological speciation and its alternative. Science 323: 737-741.

Sletvold N, Grindeland JM, Ågren J. 2010. Pollinator-mediated selection on floral display, spur length and flowering phenology in the deceptive orchid Dactylorhiza lapponica. New Phytologist 188: 385-392.

Smith SD. 2010. Using phylogenetics to detect pollinator-mediated floral evolution. New Phytologist 188: 354-363.

Smith SD, Ane C, Baum DA. 2008. The role of pollinator shifts in the floral diversification of Iochroma (Solanaceae). Evolution 62: 793-806.

Sprengel CK. 1793. Das Entdeckte Geheimniss der Natur im Bau und in der Befruchtung der Blumen. Berlin, Germany: Vieweg.

Thompson JN. 1998. The population biology of coevolution. Researches on Population Ecology 40: 159-166.

Vallejo-Marín M, Da Silva EM, Sargent RD, Barrett SCH. 2010. Trait correlates and functional significance of heteranthery in flowering plants. New Phytologist 188: 418-425.

Vázquez DP, Blüthgen N, Cagnolo L, Chacoff NP. 2009. Uniting pattern and process in plant-animal mutualistic networks: a review. Annals of Botany 103: 1445-1457.

Venail J, Dell'Olivo A, Kuhlemeier C. 2010. Speciation genes in the genus Petunia. Philosophical Transactions of the Royal Society B: Biological Sciences 365: 461-468.

Vereecken N, Cozzolino S, Schiestl F. 2010. Hybrid floral novelty drives pollinator shift in sexually deceptive orchids. BMC Evolutionary Biology 10: 103 .

Waser NM, Chittka L, Price MV, Williams NM, Ollerton J. 1996. Generalization in pollination systems, and why it matters. Ecology 77 : 1043-1060.

Weis AE, Kossler TM. 2004. Genetic variation in flowering time induces phenological assortative mating: quantitative genetic methods applied to Brassica rapa. American Journal of Botany 91: 825-836.

Key words: candidate genes, evolutionary dynamics, evolutionary pollination ecology, mutualism, pollinator-mediated selection, quantitative genetics.

\section{The invasion of the land by plants: when and where?}

The origin of land plants was one of the most important events in the history of life on Earth. It was a major macroevolutionary event in its own right, with profound ecological consequences, but it also had enormous effects on the environment of planet Earth, altering atmospheric composition, weathering and soil formation, etc., and hence climate and biogeochemical cycles. Understanding the timing of the origin of land plants is a long term goal. In this issue of New Phytologist, Rubinstein et al. (pp. 365-369) provide new evidence that this event occurred 8-12 million yr earlier than previously accepted.

\section{'Thus, although reports are currently few, attention is turning to the possibility that the centre of origin of land plants may have been located on Gondwana.'}

The land plants (Embryophytes) are a monophyletic group that evolved as an adaptive response to the migration from a freshwater aquatic to terrestrial subaerial habitat. Phylogenetic analysis of extant plants suggests that charophycean green algae share a sister group relationship with the Embryophytes, that is, the land plants probably evolved from a freshwater aquatic multicellular green alga similar to extant Chara and Coleochaete (Graham, 1993). Within the Embryophytes liverworts are the most basal group, followed by mosses, and then hornworts and vascular plants sharing a sister group relationship (Qiu et al., 2006). However, it is to the fossil record we must turn if we are to understand what the first land plants were like and when and where they evolved.

Traditionally the earliest evidence for land plants was actual megafossils (fossils representing a significant portion of the plant). Until the late 1950s the simple rhyniophytoid plant Cooksonia provided this benchmark (Lang, 1937), and it is still the oldest generally accepted megafossil, being reported from the Late Silurian (late Wenlock) (Edwards et al., 1983). However, evidence from a new technique called palynology became widely available from the late 1950s. This technique involves dissolving rock to release 